\title{
Exploring Gaps between the Need and Reach for Training Programmes in Higher Education through Teacher Reflections
}

\author{
Dr. Sophia Gaikwad*1, and Dr. Ashwini Wadegaonkar² \\ ${ }^{1}$ Head, Symbiosis Teaching Learning Resource Centre, Symbiosis International (Deemed \\ University), Pune, India \\ ${ }^{2}$ Assistant Professor, Symbiosis Teaching Learning Resource Centre, Symbiosis \\ International (Deemed University), Pune, India \\ ${ }^{1}$ head_stlrc@siu.edu.in, 2ashwini.wadegaonkar@siu.edu.in
}

\begin{abstract}
Through a comprehensive needs assessment, an institution can establish its training goals for capacity building and professional development of teachers. The purpose of this study is to guide and encourage researchers and other significant stakeholders working in the field of teacher training and faculty development, to understand the common trends in the training programmes. Thus, helping them to explore aspects related to needs and gap analysis of the demands and accessibility to the training facilities provided by the university/management. The data were collected from 178 university teachers chosen from two different university set-ups - a State University and a private University. Questionnaire was developed to recognize the needs related to nature of training programmes. Also, semi-structured interviews were conducted to discover the current status of the teacher training in the Higher Education from the filed experts, followed by triangulation for exploring the gaps between 'Need and Reach' of the training programmes. The results clearly revealed that there exist many gaps considering the 'receive and impart' or 'demands and accessibility' of the training provided by the universities in the context of - knowledge, skill enhancement, continuity, flexibility of selection, quality, right approach towards the training, andragogy, etc.
\end{abstract}

Keywords: Teacher training, need analysis, Gap identification, Need and Reach of training programmes, higher education, University set-up

\footnotetext{
* Corresponding author.
} 


\section{Introduction}

We are living in an era of explosion of not only knowledge but also changes! The reason behind this is - first being the thirst for quality \& excellence and excessive \& compulsive competition being the second. Today it is no longer sufficient for the faculty in higher education to be only good researchers, but it is equally important for them to be able to impart quality education. Research supports the central importance of teachers' training and professional development in improving and/or boosting the quality of education [6]. Training has specific goals of improving one's capability, capacity, productivity and performance. Activities conducted in the vocational and professional training must provide apprentices and professional newcomers with conceptual knowledge, technical skills, work experience, social aptitude and self- competency [29]. Training needs analysis in any educational institution is a dynamic process that helps to determine the specific needs for future training. Eventually this helps in designing the specific training programs to provide their employees for them to become productive and efficient [18]. Getting qualified teachers could be achievable, but getting trained teachers will always remain a challenge. With the ever increasing demand and awareness about quality it becomes imperative to incorporate these training trends in the teaching-learning set up of the university. The UGC Academic Staff colleges in India and many TeachingLearning Centres across the globe suggest the same. Through a comprehensive need assessment, an institution can establish its training goals regarding the nature, quality, and accessibility of the training programme for capacity building and professional development of teachers. This is the very purpose of undertaking the present research.

\section{Related work and literature review}

The purpose of the review undertaken is to understand the area of study and to identify the research gap in existing literature. The related researches and literature have been reviewed considering the following major themes:

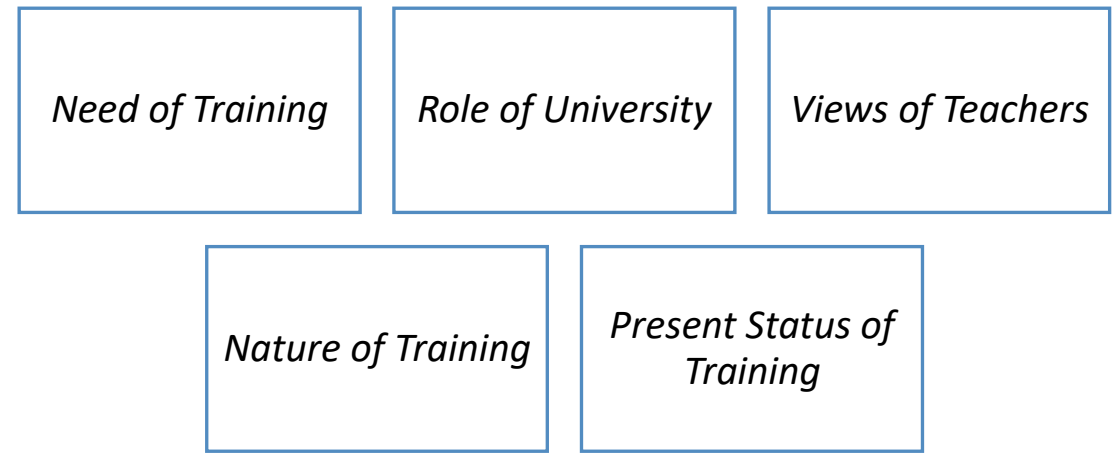

\section{Figure 1: Major themes for literature review}

With respect to need of training, it was found that many university teachers consider pedagogical training as a valuable tool in their teaching practice and are in favor of pedagogical training courses and that training has positive effect on teachers' approach to teaching and on their teaching methods [30]. In recent times when the need to improve university teachers teaching skills and pedagogical thinking is acknowledged to be essential [22], it is equally true that training needs must be understood as a process of lifelong learning, and the interconnection of scenarios for training and work, as training plays a key role in professionalization [8]. Thus, needs assessment studies have to be 
conducted, for use by policy makers on the basis of a baseline of relevant research data [2].

Programmes of professional development for staff must find ways to enhance skills [16], as need analysis help institutions to analyze the short-term and long term needs for their initiatives, and are instrumental in development of strategies [4]. While we acknowledge the importance of training, there are some who consider the effect of teacher's training in higher education questionable, they note that there is only little evidence to show that training would have an effect on teaching behavior. According to Gibbs, G. \& Coffey, M. (2006) there is very little evidence that training university teachers makes any difference. But despite this difference of opinion there are enough studies which reveal the need for faculty training, the need to create a teaching plan including organizational as well as design aspects, and incorporating skills that deal with the new Higher Education setting, together with technical-pedagogical themes which may satisfy the faculty needs $[7,15]$.

It would also be worthwhile to note that, the most effective indicator of the success of any university would be its students and the change they are bringing about in the society. Universities have a great responsibility towards faculty training if they wish for their centers and schools to be able to stand-up to new challenges and be up to date both in terms of the scientific knowledge within their scopes and in terms of pedagogical advances says Diaz, M., Santaolalla, R. \& Gonzalez, A. (2010). Faculty development programs (FDPs) have proven to be successful for improving teaching skills in higher education [14]. The quality of higher education definitely depends a lot on the quality of its teachers [26]. To organize effective training programmes it is important to ensure that resources do not go to waste and thus there is a need to conduct a thorough analysis of training needs for staff training. This can certainly be the key to create productive workforce in any organization [28]. The commitment of the university towards faculty/ staff development is of utmost importance because a staff training programme is most unlikely to succeed, unless the university, in which it takes place, demonstrates its commitment to it [9]. Thus, university has a significant scope to improve quality of teaching, and subsequently the learning. This area has been observed to be relatively unexplored and needs more concrete research studies to understand the mechanism and role of universities and management to take up need based training programs for teachers.

Taking the views of teachers into consideration for planning the faculty training programmes, is also very important because their commitment to these training programmes is of great relevance in this context. In fact, shorter training seems to make teachers more uncertain about themselves as teachers [21]. According to Diaz, M., et.al. (2010) faculty training must be structured with a starting point in mind, one that facilitates the creation of syllabi and pedagogical approaches that lead to the achievement of recognized professional qualifications for students [11]. Teachers' voices are important and need to be considered for effective and suitable professional development [1].

Teachers' role can be defined under four sub-roles, those of: Teacher, Researcher, Consultant, Manager of the education process, (Binsted, D. 1980). Education through groups of teachers with similar needs either due to their affinity to a scientific scope or due to their responsibilities as teachers should be incorporated in to the training methodology of the state [8]. In the higher education culture, often more value is given to research over teaching or even denigrates teaching is denigrated. In this context, some trainers saw programmes as having a role in redressing this balance by ascribing value to 
teaching and establishing positive attitudes [11]. It is felt that more than mastery over teaching skills, teachers' own concern about the fields where they do not feel knowledgeable, need to be considered [17].

The nature of training is a major concern considering the varied needs of teachers, Veniger, K. (2016). Institutes should offer teaching support to teaching staff and establish special development centres on higher education learning and also provide research [30]. A few years of probations and training should be required before one can officially become a teacher in higher education settings [13]. The emerging research based recommendations support preferred thematic orientations and alternative forms of inservice training [31].As per the European Commission 2005 - Teacher Competences and Qualifications: A lecturer's training and professional development should be considered a lifelong task, which should consequently be structured and funded [10]. The ideal approach would be to establish an uninterrupted continuum of training and education that spans from initial teacher training to joining the professional development throughout the whole career including formal, informal and non-formal opportunities. It is necessary to embrace the internationalisation of trainer and education, both initial and continuing. The exact nature and the best mode of delivery of training seems very dependent on the type and size of centre, the conditions of employment for staff and the proximity to training providers [16]. Recognizing teachers' educational deficiencies and providing continuous training, based on the reflexive responses has been recommended [24].

Present status of training show two faces, a positive improvement and the other, as not so good as various researchers report it. The status of quality teaching in higher education is vital for learning, but university teaching staffs in Europe are not as well prepared for their teaching career as for research and the pedagogical qualification of university teachers is often taken for granted in academic culture [30]. Henard, F. \& Leprince - Ringuet, S. (2008) reports that 'the quality teaching is receiving very little attention as compared to teaching' [13]. The development of faculty has been studied in higher education and it is recognized that there is a lack of teaching knowledge and skills in most academic departments [25]. It was found that there is little evidence regarding the impact of training teaching and even less evidence of impact on student learning and involves relatively sophisticated processes underpinned by theoretical models of professional development [11]. In comparison to primary and secondary teachers, most college and university professors received minimal or no training in educational theory and methodology [23]. The focusing principles for teacher training are - Teacher-Industry connections, Empowering with technical skills and Application of teaching technologies [12]. A training of university teachers has recently become a widespread trend in many countries [21].

India's Higher Education system is the third largest system in the world. Apart from the quantity and quality enhancement the major challenge lies in teacher competency building and professional development across all the Higher education institutes in the country. The review has brought about some interesting facts that the universities have a special responsibility to train the teachers and support that there is an urgent need explore the identification of gaps between need and reach of the training programmes. 


\section{Conceptual framework}

The term 'Needs' for this research represents the demands of teachers in the university set up related to training programmes considering - (A) Nature of the training programmes being offered, that includes: Areas of preferred training, Level of training, Frequency of the training programmes, Mode of instruction, Duration of the training programmes and the Formal Mechanism. It also includes (B) Quality of the training programmes: Benefits of the training programmes, Skill enhancement, Best and worst training programmes attended in the past, Information about the training programmes, Role of management, Efforts taken by the management, and the Initiatives by management. On the other hand the term 'Reach' refers to the accessibility to the training facilities provided by the university to all its teachers and the ways \& means through which the training reaches them. It includes - Nature and functioning of the training programmes, Current status of the teacher training programmes and required reforms, Role of management and Methods of training needs identification. The diagrammatic representation can be seen as -



Figure 2: Conceptual framework for the study

\section{Research methodology}

\subsection{Research questions}

1. What are the Training Programme needs of teachers teaching in Higher Education institutions?

2. What are the gaps between needs and reach to the training facilities provided by the Higher Education institutions? 


\subsection{Research design}

The research follows 'QUAN + qual - Simultaneous' approach [19]. To come to the combined data interpretation through triangulating the results from the survey and interview data, allowed the authors to posit a gap analysis between the 'Need and Reach' in training programmes of teachers in Higher Education.

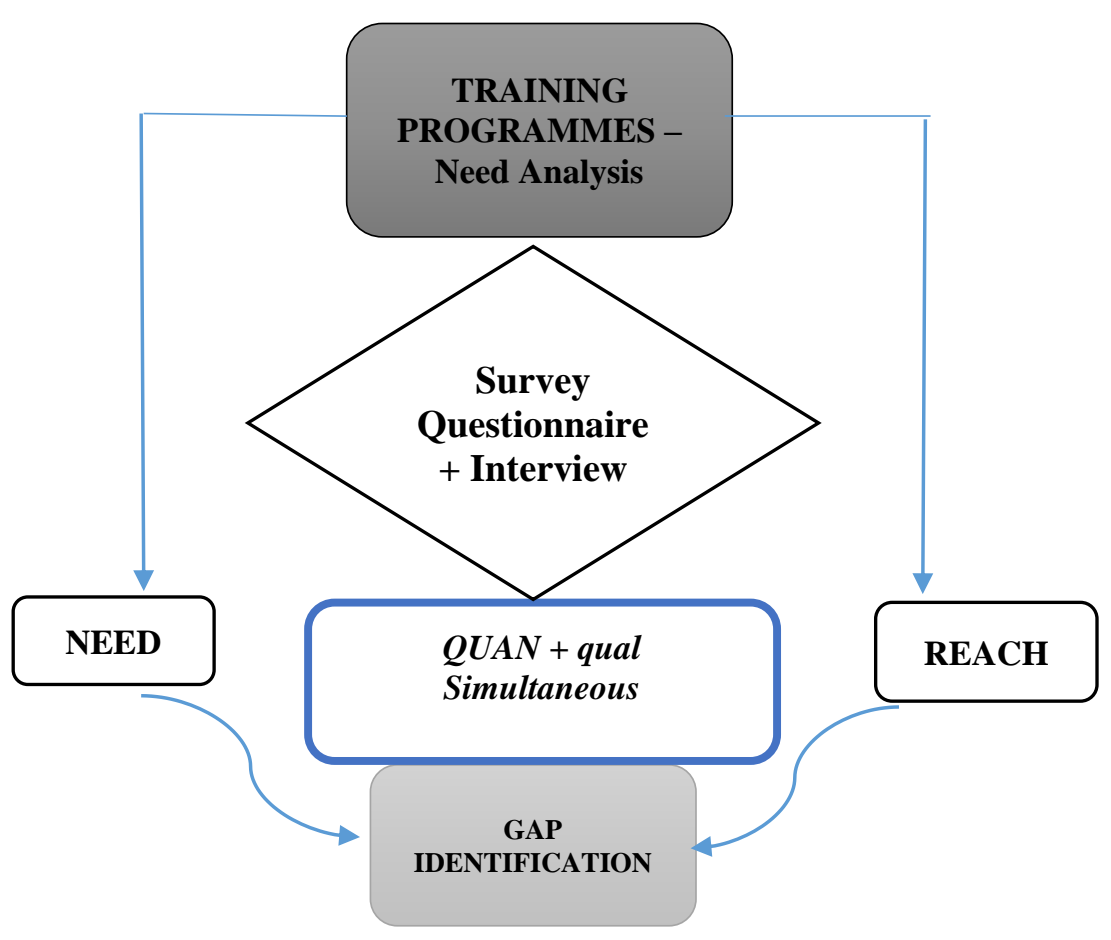

Figure 3: Research design

\subsection{Method and Sample}

A cross sectional survey design was used to collect reflections of teachers in Higher Education institutions and the experts in the field of training and professional development of teachers were interviewed to identify the gaps in the 'needs and reach' for the training provided by the institutions in the University set-up.

Responses from 61 teachers from colleges affiliated to the State University (SU) and 117 from Deemed University (DU) were gathered. These teachers $(\mathrm{N}=178)$ were from various academic disciplines as - Law, Management, Media, Communication \& Design, Engineering, Computer Science, Health Sciences and Humanities \& Social Studies. The respondents were Assistant Professors (67\%), teaching assistants / associates / lecturers (24\%) and full professors (8\%), teaching at Undergraduate and Postgraduate level. 


\subsection{Data collection}

\subsubsection{Questionnaire}

The purpose of the questionnaire is to understand the nature and quality of the training programmes and teacher preferences over the same.

a) Reliability of the tool: A series of drafts were made and the questionnaire was finalized based on the views, suggestions and inputs of two subject experts.

b) Validity of the tool: The questionnaire was tested for Face validity, construct validity and content validity.

c) Design of the Questionnaire: The questionnaire consisted of 4 sections and 19 questions were grouped into three section: (I) Teachers interest in training, (II) Teachers' views/ motivation about the training; (III) Management / higher authorities' role in training and (IV) Participants' professional information. Some of the questions were formulated closed ended. The following types of closed ended questions were used: Likert - Scale, Yes - No items and multiple choice items. The 5-point Likert Scales with descriptive terms as response options adapted to the relevance of the question. For example: 5- Outstanding, 4Exceeded Expectations, 3- Met Expectations, 2- Needs Improvement, 1- Poor (with 1 as poor and 5 as Outstanding). The multiple select multiple choice questions were used. The survey was conducted by the researcher in person, with prior consent of the participants and the experts.

\subsubsection{Interview}

With the purpose to understand the nature and current status of the training programmes, six expert professionals (> 10 years of experience) in the field of teacher training and professional development, were interviewed. The semi-structured interviews were conducted for the exploration of the perceptions and opinions of experts who provide teacher training in person. Each interview was conducted for the duration of 1 to $1 \mathrm{hr} .30$ minutes duration approximately. The responses were recorded on the spot and then analyzed.

\section{Analysis and Interpretation}

After the collection of raw data, it was arranged and edited. Primary data obtained from the field survey was compiled, tabulated and presented in the form of frequencies and percentages for ease of analysis. The data were analyzed using IBM SPSS 2. The data analysis was summarized and findings presented in tabular form. The data analysis was then organized and classified according to the questions pertaining to the purpose and relevant issues regarding 'Need and Reach' of training programmes.

Qualitative data was derived from the responses of the experts to the open ended semistructured questionnaires. The responses were structured considering - descriptive narratives to categorise and thematize the data. This was used to answer the research questions since this information carried the themes in the research questions. The quantitative and qualitative data were mapped to identify the gaps between 'Needs' and 'Reach' of the training programmes. The data were analyzed and interpreted using the following framework (Table 1) 
Table 1: Framework for data analysis and interpretation

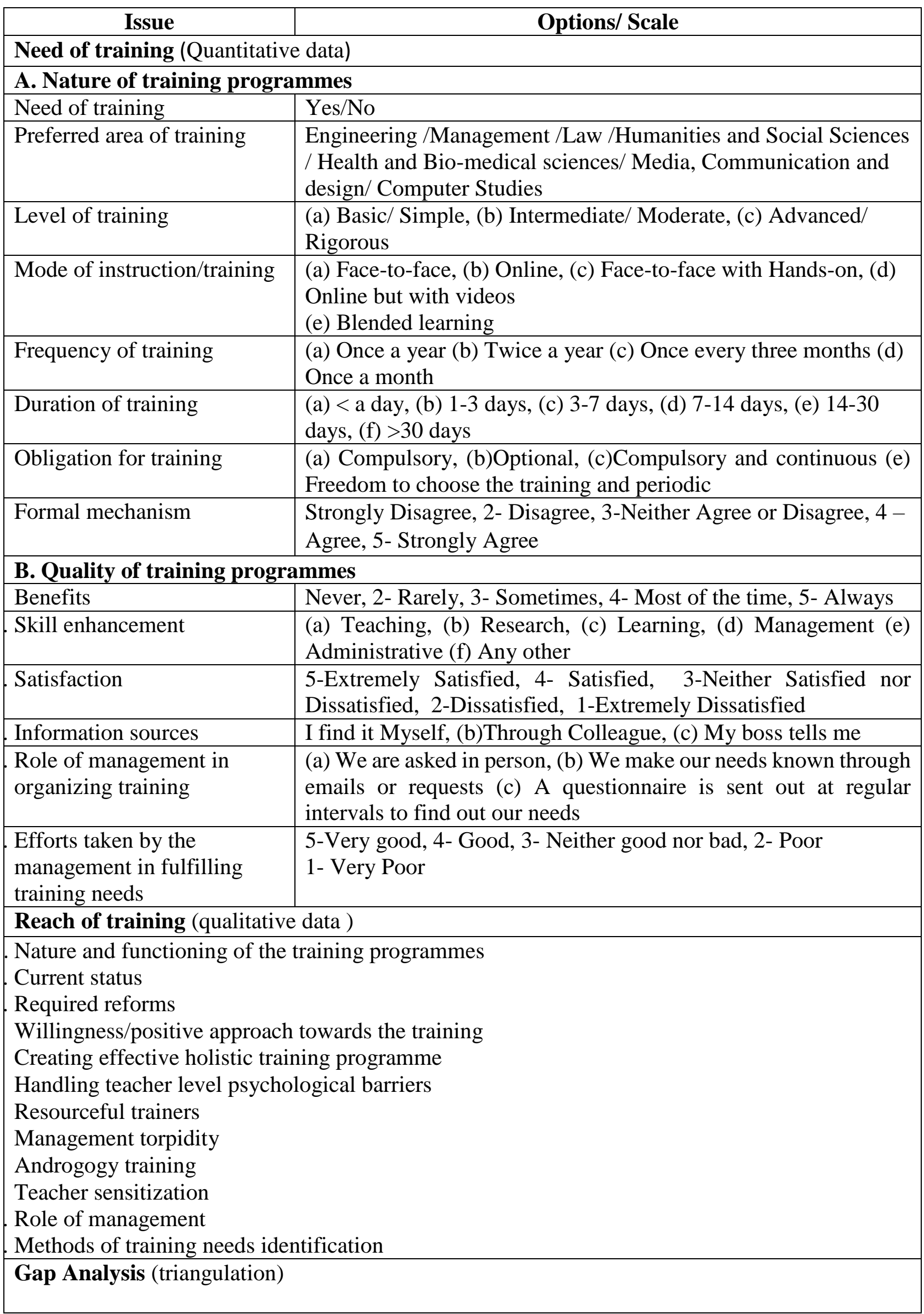




\section{Results}

\subsection{Quantitative (Survey): NEEDS - Nature of training programmes}

1. Need of training - Training is essential. Teachers. Teachers from both the universities have given preference to training programmes which are need based, related to content, personality of the faculty, methodology of teaching and conducted at frequent intervals throughout the year.

2. Preferred areas of training - Subject specific knowledge

3. Level of training - Advanced (DU), Intermediate (SU). Basic level training was not preferred.

4. Mode of instruction/training - Face to face with hands on training was preferred over online or blended mode.

5. Frequency - DU: Twice a year, SU: Once a year was preferred.

6. Duration - DU has the preference for 1 to 3 and 3 to 7 days while SU has preferred 7 to 14 days

7. Obligation for training - It was found that teachers both from both the universities have preferred for Freedom to choose the training and periodicity of training programmes.

8. Formal mechanism - The faculty members from both DU and SU felt that a formal mechanism established by the University would be of great relevance. But it is remarkable that almost $58.6 \%$ of the faculty members from SU are indecisive about having a formal mechanism of training. Teachers supported there should be a formal mechanism for the training programme established by the university and followed universally"

9. Obligation for training - It was found that teachers from both the universities have preferred for 'Freedom to choose the training and periodicity of training programmes'. It is noteworthy that some teachers felt that training must be compulsory and continuous.

\subsection{Quantitative (Survey): NEEDS - Quality of training programmes}

8. Benefits - Acknowledged the contribution of training programmes in their teaching and most of the time they were benefited.

9. Skill enhancement - Top 3 skills enhanced due to previously attended training programmes are found to be Teaching, Learning and Research

10. Satisfaction - Most of the teachers found that training programmes attended so far have exceeded their expectations.

11. Information sources - Teachers search information about the training programmes mostly on their own or sometimes from their colleagues.

12. Role of management - teachers inform management about their training needs mostly through emails or request and many of them are asked in person by the management.

13. Efforts taken by the management- Teachers felt that efforts taken by their university/ management for fulfilling their training needs are good but some of them felt that it is neither good nor bad. Most of the teachers felt that the training initiatives taken by the university/management are satisfactory.

\subsection{Qualitative (Interviews): REACH}

14. Nature and functioning of the training programmes -

- Training is that which covers the gap between the performance right now and the expected performance. 
- Training is essential for - building up qualities and skills, Improving performance, Professional growth

15. Current status -

- Respondents pointed out many concerns and constrains during the discussion about the ratio between faculty eager / keen to receive training versus higher management keen to impart the training.

- In service training is provided in the form of Orientation and Refresher courses.

- Training severely lacking in content and skills, style of teaching.

- Major objective of training is mere getting certificates.

16. Required reforms -

- Willingness/positive approach towards the training - Training needs should be identified the corporate way, considering whether training is attended willingly.

- Creating effective holistic training programme - 60\% crowd is interested, $40 \%$ is not but with training you can make them interested. So it is about having an effective, holistic training programme in place.

- Handling teacher level psychological barriers - Teachers don't give up their own prejudices, biases so there are a lot of psychological elements even beside the training component, and we need to work on both. It was observed that sometimes teachers get defensive and not willing to participate.

- Resourceful trainers - Willingness to join the training programme also depends on the kind of trainers. Need of good trainers is urgent.

- Management torpidity - The major institutional level constrain is when the management is not willing to send the teachers for training

- Androgogy training - Training of different teaching methods is required as most teachers are still using the traditional method, black board method or marker / chalk method and people are really - really reluctant to use other method.

- Teacher sensitization -. Along with technical knowledge instilling moral values should also be the focus of training programmes. Also attention must be paid on the skill oriented training and towards students of deprived classes.

- Training from the beginning, in workshop mode, interactively.

- One month induction programme for the novice teachers

- Instead of 28 days Orientation programme it can be at least $14 / 15$ days or 7 days. (4 programmes of 7 days). If it is 7 days programme then at least 4 days should be face to face and 3 days assignment etc. can be online.

- Need to encourage face to face interaction with appropriate use of technology

- Online courses like MOOCs etc. and emphasized on use of technology based learning for the training purpose

\section{Role of management}

- Initiatives taken by management for training

- There are few institutes where management is really thinking about the faculty training. Management is happily ready to relieve the faculty if it is during the vacation but if training comes between the college duties then they don't send.

18. Methods of training needs identification

- Personal interaction with teachers 
- Interactions based on experience and gender.

- Creating awareness among the teachers

- The needs analysis of the teachers using the university website and plan the training accordingly

\subsection{Gap Analysis}

The triangulation of the above results yielded the gaps in the 'Need and reach' in the current training programmes, as -

1. Lack of training for need specific - knowledge, skills in teaching-learning.

2. Skill analysis with respect to Teaching, Learning, Research and other andragogical practices and designing courses as per the need

3. Reduce alienation between student and teacher to humanize education

4. Lack of new mechanisms in teaching

5. Lack of perspectives about the content and skills, styles of teaching

6. Right approach towards training - $80 \%$ teachers take training only for the sake of certificates.

7. Consecutive continuous training is required.

8. Blended mode of training, Hybrid instruction model

9. Flexibility in selection of the programme - Short term programmes, with more frequency

10. Standardization and institutionalization of the training - Systematic process of data collection and need analysis

11. Common, user-friendly platform to share information of upcoming courses

12. More efforts to improve quality and quantity of training programmes.

\section{Discussion and Implications}

Over the past 20 years, universities and other institutions of higher education all over the world have been in a state of rapid change and nowhere more so than in developing countries, where the societies in which they serve have themselves undergone very radical changes says Elton, L. \& Manwaring, G. (1981). Preparation and professional development of faculty members has gained the attention of educational institutions all over the world [3].

Thus we see that training in higher education plays a very important role achieving the desired outcome of effective and trained teachers in the light of National Education Policy-2020. According to Diaz, M., Santaolalla, R. \& Gonzalez, A. (2010), faculty training must be structured with a starting point in mind, one that facilitates the creation of syllabi and pedagogical approaches [8].

In the study conducted on teacher's perception on Professional development (PD), it was found that teachers expressed a belief in the importance of PD and its role in the improvement of teaching practice, motivation and communication [20]. And the researchers feel that this approach can definitely help bridge the gap between training needs and the ways and means through which training reaches the faculty members. Findings revealed the preference over own subject knowledge development found to be similar to the previous research study that 'updating subject knowledge through industrial attachments was a major training and development need for teachers' [5]. A serious concern was put forth by Smith, E. (2010) that teachers and trainers do not have adequate skills to work skillfully and critically with Competency Based Training, leading to thin pedagogy in the Australian vocational education scenario [27]. 
It was indicated through the previously conducted study that the design of a training programme has the strongest impact on post-training job performance, and also on the self-efficacy and post-training behaviour, stressing the importance of considering the need analysis of nature of training programme [7]. In the light of these findings it can be concluded that various studies support that training programmes must be need based analysis and should reduce the gaps between demands of the teacher trainees and the accessibility to the training facilities provided by the university/management.

This study is limited to a convenience sample of teachers teaching in two different university setups - State and Deemed universities were participated in the study, from Pune city, state of Maharashtra in India, and the need analysis was conducted considering the nature, quality and accessibility of the training programmes provided by the university management. In spite of these limitations, this study is of interest to the trainers, researchers and practitioners in the educational training and development. The results will be useful in design and development of faculty development and capacity building programmes for the higher education institutions. The Study will guide the decision making in finalization of the nature of these programmes and also will be a ready reference to the trainers on understanding the needs and reach of the future training programmes, considering the identified gaps.

\section{Conclusion}

The research clearly identified the need for training programmes for the university teachers. All the respondents have clearly stated that training is of great importance as it acts like a bridge between lack of knowledge and better performance. The respondents were quite unhappy with the present state of higher education because there are teachers who are proficient in their own subject but severely lack the teaching skills. It is recommended that training should be continuous, need based with use of technology and that lot of efforts should be taken to identify the right trainer. Emphasis should be given to the standardization and institutionalization of the training programmes. One of the most important factor that work towards or against the success of a training programme is the prejudice or the mind-set of the teachers. Respondents also feel that Technology should not be ignored and along with technical knowledge, and instilling moral values and ethics should also be the focus of training programmes.

There exist many gaps considering the 'Need and reach' of the training provided by the universities in the areas of knowledge building, skill enhancement, continuity in training, flexibility to select the training programme, maintaining quality, right approach towards the training, andragogical considerations, duration, mode and frequency of the training programme. etc. Thus it is confirmed that efforts need to be taken for identification of training programme needs and formal mechanism can be provided for continuous faculty development. The findings of this study will facilitate the process of decision-making and planning of training programmes in terms of the nature - level, duration, frequency and mode of training along with the specific needs of specific group of teachers related to - subject knowledge, educational technology, skills enhancement. 


\section{Acknowledgements}

The authors have read and approved the final paper. The authors would like to acknowledge all the participants and experts who participated willingly in this study and appreciate their time and efforts. The participants and experts were informed prior to the study and consent was taken about their anonymity, nature \& purpose of the data obtained through the study.

The authors have no conflicts of interest to declare. The Author and Co-author have seen and agree with the contents of the manuscript and there is no financial interest to report. We certify that the submission is original work and is not under review at any other publication. The authors disclosed receipt of the following financial support for the research, authorship, and/or publication of this article: This work was supported by the Symbiosis International (Deemed University).

\section{References}

[1] AL-Qahtani, Hind M. (2015). Teachers' Voice: A Needs Analysis of Teachers' Needs for Professional Development with the Emergence of the Current English Textbooks. English Language Teaching; Vol. 8, No. 8; 2015 ISSN 1916-4742 E-ISSN 1916-4750.

[2] Ali, R., Khan, M. S., Ghazi, S. R., Shahzad, S., \& Khan, I. (2010). Teachers' training-a grey area in higher education. Asian Social Science, 6(7), P43.

[3] Abouelenein, Y. A. M. (2016). Training needs for faculty members: Towards achieving quality of University Education in the light of technological innovations. Educational Research and Reviews, 11(13), 1180-1193.

[4] Azimi, H. M. \& Rahmani, R. (2013). Importance of Needs Assessment for Implementation of E-learning in Colleges of Education. International Journal of Information and Computation Technology. ISSN 0974-2239 Volume 3, Number 5, pp. 377-382.

[5] Bakah, M.A.B., Voogt, J.M. and Pieters, J.M. (2012). Curriculum reform and teachers' training needs: the case of higher education in Ghana. International Journal of Training and Development, 16: 67-76. https://doi.org/10.1111/j.1468-2419.2011.00389.x

[6] Boudersa, Nassira. (2016). The Importance of Teachers' Training Programs and Professional Development in the Algerian Educational Context: Toward Informed and Effective Teaching Practices. Expériences Pédagogiques. 01.

[7] Diamantidis, A.D. and Chatzoglou, P.D. (2014), Employee post-training behaviour and performance. International Journal of Training and Development, 18: 149170. https://doi.org/10.1111/ijtd.12034.

[8] Diaz M. J., Santaolalla R. C. \& Gonzalez A. G. (2010). Faculty Attitudes and Training Needs to Respond the New European Higher Education Challenges. 'Higher Education', Vol. 60, Issue 1, $101-118$. 
[9] Elton L. \& Manwaring G. (1981). Training and Education of Teachers in Higher Education in Developing Countries. 'Higher Education', Vol. 10, Issue 2, 131 - 140.

[10] Fernanadez J. T. (2013) Professionalization of teaching in Universities: Implications from a training Perspective. 'RUSC, Vol. 10, Issue 1, 345 - 358.

[11] Gibbs G. \& Coffey M. (2004), The Impact of Training of university teachers on their teaching skills, their approach to teaching and the approach to learning of their students. 'Learning in Higher Education', Vol. 5, Issue 1, 81 - 100.

[12] Gormaz-Lobos, D., Galarce-Miranda, C., Hortsch, H., \& Vargas-Almonacid, C. (2021). Teacher Training's Needs in University Context: A Case Study of a Chilean University of Applied Sciences. International Journal of Emerging Technologies in Learning (iJET), 16(09), pp. 119-132. https://doi.org/10.3991/ijet.v16i09.21389

[13] Henard F. \& Leprince - Ringuet S. The path to Quality Teaching in Higher Education, retrieved from https://www1.oecd.org/edu/imhe/44150246.pdf

[14] Kamel AM. (2016). Role of faculty development programs in improving teaching and learning. Saudi J Oral Sci 2016;3:61-8.

[15] Khan M. N. \& Sarwar, M. (2011). Needs Assessment of University Teachers for Professional Enhancement. International Journal of Business and Management Vol. 6, No. 2.

[16] Mcnamara, G., Mulcahy, C. and OíHara, J. (2005). An analysis of the training needs of staff in the Further Education sector in the Republic of Ireland. Journal of Adult and Continuing Education - Volume 11 No. 2

[17] Moeini, H. (2008). Identifying Needs: A Missing Part in Teacher Training Programs. Seminar.Net, 4(1). https://doi.org/10.7577/seminar.2488

[18] Morrison, K. (2019). What training needs analysis is and how it can benefit your organization. e Learning Industry.

[19] Morse, J. M. (1991). Approaches to qualitative-quantitative methodological triangulation. Nursing Research, 40, 120-123.

[20] Nasser, R. and Romanowski, M. (2011), Teacher perceptions of professional development in the context of national educational reform: the case of Qatar. International Journal of Training and Development, 15: 158-168. https://doi.org/10.1111/j.14682419.2011.00377.x

[21] Postareff L., Lindblom S., Ylanne, Nevgi A. (2007). A follow-up study of the effect of pedagogical training on teaching in higher education. Springer Science + Business Media, 29- 43.

[22] Pastareff L., Lindblom S. - Ylanne, Nevgi A. (2007). The Effect of Pedagogical Training on Teaching in Higher Education. 'Science Direct - Teaching and Teacher Education', 
$23,557-571$.

[23] Robinson T. E. \& Hope W. C. (2013). Teaching in Higher Education: Is there a need for training in pedagogy in graduate degree programs? 'Research in Higher Education Journal', AABRI Journals, 131564, 1 - 11 .

[24] Rodríguez Jiménez, Andrés, Miqueli Rodríguez, Bertha, \& Dávila Valdés, Yosdey. (2021). Identification of continuing training needs for teachers in the face of 21st century educational demands. Actualidades Investigativas en Educación, 21(1), 284317. https://dx.doi.org/10.15517/aie.v21i1.44073

[25] Rowbotham, M. A. (2015). The impact of faculty development on teacher self-efficacy, skills and retention (IERC FFR 2015-1). Edwardsville, IL: Illinois Education Research Council at Southern Illinois University Edwardsville.

[26] Sarkar, A., Bharani, R., Ganger, S., \& Balsubramanian, G. (2015). Effectiveness offaculty development programs in developing teachers for higher education. Conference: "Skill Development: The Key to Economic Prosperity" At: Mumbai. Volume: 3. https://www.researchgate.net/publication/289790676_EFFECTIVENESS_OF_FACULT $Y \_D E V E L O P M E N T \_P R O G R A M S \_I N \_D E V E L O P I N G \_T E A C H E R S \_F O R \_H I G H E R \_E$ DUCATION. 10.11am, 12/2/21

[27] Smith, E. (2010). A review of twenty years of competency-based training in the Australian vocational education and training system. International Journal of Training and Development, 14: 54-64. https://doi.org/10.1111/j.1468-2419.2009.00340.x

[28] Syanda, P.M., Nyamanga, E. A., Walter Bichang'a, W. \& Nyongesa, W.J. (2014). Assessing the Extent to Which Staff Training Needs are Analyzed at Kenya Polytechnic University College, Nairobi. Information and Knowledge Management www.iiste.org ISSN 2224-5758. ISSN 2224-8

[29] The impact of skills and training on local development (11 October 2021) [Editorial]. International Journal of Training and Development Volume 25 Issue 4pp. 341-449. 96X (Online). Vol.4, No.9.

[30] Veniger K. A. (2016). University teacher's opinions about higher education pedagogical training courses in Solvenia. CEPS Journal, Vol. 6, Issue 4, 141 - 161.

[31] Yiasemina Karagiorgi \& Loizos Symeou (2007) Teachers' in-service training needs in Cyprus, European Journal of Teacher Education, 30:2, 175 194, DOI: 10.1080/02619760701275487 